10-1-2002

\title{
A Peer-reviewed Program for Senior Proficiencies
}

Cheryl Delgado

Cleveland State University, c.delgado@csuohio.edu

Bonnie Mack

Follow this and additional works at: https://engagedscholarship.csuohio.edu/nurs_facpub

Part of the Nursing Commons

How does access to this work benefit you? Let us know!

\section{Publisher's Statement}

Copyright @ 2002 Wolters Kluwer Health, Inc. Lippincott Williams \& Wilkins

\section{Recommended Citation}

Delgado, Cheryl and Mack, Bonnie, "A Peer-reviewed Program for Senior Proficiencies" (2002). Nursing Faculty Publications. 9.

https://engagedscholarship.csuohio.edu/nurs_facpub/9

This Article is brought to you for free and open access by the School of Nursing at EngagedScholarship@CSU. It has been accepted for inclusion in Nursing Faculty Publications by an authorized administrator of EngagedScholarship@CSU. For more information, please contact library.es@csuohio.edu. 
$M$ Many nursing programs require a review and retest of skilled procedures before graduation. In this way, the nursing school takes steps to ensure a competent graduate practitioner. At Cleveland State University this testing is known as Senior Proficiencies, and is done in the spring semester of senior year. In the past, this has been a time-consuming task for nursing resource laboratory personnel and a stressful event for students. In their course evaluations, many students expressed concern and dissatisfaction regarding their infrequently used skills and the stress associated with the retesting. The skills evaluation was a neg. ative experience for both faculty and students. Faculty members felt frustrated, and students were not afforded an opportunity for professional growth and personal development. Additionally, the logistics of moving a large number of students through a variety of scenarios to test multiple selected skills from multiple prior courses, with adequate supervision and review from nursing resource laboratory personnel and faculty, became burdensome and was not cost effective. A change in the way Senior Proficiencies were done was necessary.

\section{Student Issues}

\section{A Peer-reviewed \\ Program for Senior Proficiencies}

Cheryl Delgado, MSN, RN, BC-ANP

Bonnie Mack, MSN, RN

\section{Theory}

Based on cooperative learning theories, the nursing resource laboratory supervisor and other faculty members thought that a peer review evaluation would be less stressful for the students, promote retention of skills, and more efficiently use nursing laboratory resources in terms of personnel, equipment, and time. Zafuto ${ }^{1}$ and $\mathrm{O}^{\prime}$ Donnell ${ }^{2}$ have stated that cooperative learning strategies can promote learning in diverse student populations and can enhance understanding and acquisition of concrete, complex skills and procedures. Berbiglia et al. ${ }^{3}$ advocate gaming and other active learning activities that amplify the content by using what the student already knows and how the student processes incoming information. The learning theory espoused by Knowles includes 2 important learning requisites: learners need to participate actively in the learning process, and learners need to share responsibility for the learning experience. Browning and Seymour ${ }^{5}$ state that traditional teaching strategies are yielding to learning strategies that are interactive and student focused rather than teacher focused. At Cleveland State, it was felt that assuming responsibility for a peer review evaluation would facilitate the student's growth toward professionalism. The peer review evaluations for senior proficiency testing were implemented in the spring semester of 1999

\section{Peer Review}

The new format eliminated the previous formal skill testing approach, and shifted the responsibility for evaluation to the students themselves. Competencies to be reassessed included parenteral injection landmarks, intravenous therapy (calculations for drug dosages and drip rates along with peripheral intravenous line insertion and maintenance), dressings and wound care, enteral nutrition and medications, urinary catheterization, tracheotomy care and suctioning, chest tube set up and troubleshooting, and blood therapy. These were divided into 2 parts, the first to be completed before midterm and the second after midterm.

The resource laboratory was available for competencies for selected hours on Wednesday, Thursday, Friday, and Saturday. A 4-day schedule was necessary because of other demands on laboratory time. A weekend day was included for scheduling flexibility. In each half of the semester, students were allowed a 3 -week period for review with self-learning activities, including posters,

Authors' affiliation: Department of Nursing, Cleveland State University, Ohio Corresponding author: Cheryl Delgado, MSN, RN, BC-ANP, Department of Nursing. Cleveland State University, 1860 East 22nd Street, Cleveland, $\mathrm{OH} 44114-4435$ (c.delgado@csuohio.edu). 
handouts, worksheets, films, and quizzes appropriate to the procedures being tested.

Manikins were used to simulate clinical situations previously learned, but with a new twist. Whereas the manikins had been used in initial skill acquisition to demonstrate optimal scenarios, they were now incorrectly set up, with the expectation that the student would identify and correct the mistakes. Student worked in pairs and evaluated their peer's performance using the guidelines in their skills textbook.

The student's role as an evaluator was to offer constructive criticism and to document the strengths and weaknesses of their performing student partner. Evaluation criteria were provided. The evaluation tool was a performance checklist with all required behaviors listed in the order to be performed. The evaluator noted if a behavior was observed or not observed. There was additional space for identification of strengths and weaknesses. As the performer, the student's role was to demonstrate competency by performing all steps of a procedure in the correct order. The role of staff was to remain available as a resource and to monitor the evaluation process, ensuring that the peer review process followed predetermined guidelines. Because 5 different scenarios or stations were set up in a large area, the nursing resource laboratory staff was able to circulate among several pairs of students who were in the laboratory at the same time. This effectively and immediately reduced the number of hours devoted by staff to the testing, but allowed the testing to be supervised to ensure accuracy and quality.

Peer review schedules were flexible, decided by mutual agreement between the student pairs, and completed within the normal hours of nursing resource laboratory operation for a 3week period following the self-directed review sessions. All documentation became part of the student's permanent record.

\section{Results}

Student evaluations $(\mathrm{N}=37)$ were completed at the end of the first implementation of the peer-review method. The findings reflected overwhelming student satisfaction with the change. All students felt that the format added to their learning experience, and only $9 \%$ felt that the review was not valuable at that point in the program. Forty percent perceived the peer review as less stressful than instructor evaluation. One student noted that an objective attitude had emerged from their clinical experiences. Forty-five percent felt that all skills tested should be retained in testing. Three percent felt additional skills should be included. Students identified additional pharmacology and cardiopulmonary resuscitation (full code reenactment) as additional skills they felt should be included.

No permanent grades were assigned, so no student "failed" the evaluation. Students who did poorly in any section of the evaluation met with faculty individually to discuss the identified areas of weakness, and action beyond this point was the responsibility of the student. Those with weaknesses who were registered in a faculty- or preceptor-guided senior practicum for the final semester could contract with their instructor or preceptor for more practice in the area of weakness, or could review further with resource laboratory personnel if they were available. The proficiency evaluation forms were placed in the student's record.

Of the self-directed review techniques, students found practice calculations of math problems, posters, printed guidelines, and worksheets most helpful. Ranked slightly lower were quizzes, films, and interactive games. Enteral feedings and injection sites were rated as the most helpful competency retest, which was not surprising, as these were skills acquired early in the sophomore year and the most remote from the competencies. Ranked lowest in helpfulness was peripheral intravenous line insertion, where $9 \%$ of students expressed a need for more training.

Comments by students on post-implementation evaluations reflected their perceptions of increased professionalism and autonomy related to flexible scheduling and independent study. Laboratory staff found that the cooperative nature of the review stimulated and reinforced learning.

Students perceived laboratory staff as encouraging, supportive, and available. Staff viewed the peer review method as less onerous. The length of time necessary for successful comple- tion of competencies by all students was shortened from an entire semester to the 2 shortened 6-week periods.

\section{Conclusions}

The peer-review format for Senior Proficiencies has now been used for 2 years with satisfactory results. Students are able to review technical skills in a nonthreatening yet effective way, laboratory personnel are optimally utilized, and the resource laboratory is now seen as a real asset to the student experience.

Benner et al ${ }^{6}$ (1999) define skilled know-how as skilled performance or embodied intelligence, knowing what to do, how to do it, and when to do it. The development of critical thinking, collaboration and cooperation, and technological skills should be measured by student outcomes, rather than course objectives, according to Browning and Seymour ${ }^{5}$ (1997). This peer-judged method for review and evaluation of Senior Proficiencies has been shown to be effective, efficient, and an opportunity for professional and personal growth for senior nursing students.

\section{Acknowledgment}

The authors thank Carolyn Discenza, Linda Garrity, Beth Meek, Mary Moore, and Judy Reeves for their creative ideas in developing and implementing the peer review program at Cleveland State University.

\section{References}

1. Zafuto MS. Cooperative learning: a means to promote metacognitive and collaborative skills in heterogeneous nursing students. J Nurs Educ. 1997;36(3):265-270.

2. O'Donnell AM, Hall RH, Hythecker VI, et al. Learning concrete procedures: effects of processing strategies and cooperative learning. J Educat Psychol. 1990;82(1): 171-177.

3. Berbiglia V, Goddard L, Littlefield $\mathrm{JH}$. Gaming: a strategy for honors programs. $J$ Nurs Educat. 1997;36(3):289-291.

4. Knowles M. From Pedagogy to Andragogy: Revised and Updated. Chicago, IL: Associated Press; 1980.

5. Browning M, Seymour RJ. Student perceptions of learning peer review and self evaluation. Tennessee Nurse. 1997; 60(3):19.

6. Benner P, Hooper-Kyriakidis P, Stannard D. Clinical Wisdom and Interventions in Critical Care. Philadelphia: WB Saunders; 1999. 